\title{
Uso de sustancias químicas para prevención o desinfección contra el SARS-CoV-2 en el ámbito extrahospitalario
}

\author{
Use of chemical substances for prevention or disinfection against SARS-CoV-2 in the out-of-hospital setting
}

\section{Sr. Editor:}

La COVID-19, es una enfermedad caracterizada por la infección del tracto respiratorio debido al SARS-CoV-2; fue declarada pandemia por la OMS, el 11 de marzo de $2020^{(1)}$. Al vernos envueltos en este problema de Salud Pública condujo a gobiernos y sectores privados de varias partes del mundo ${ }^{(2,3)}$, al uso de múltiples dispositivos que utilizan sustancias químicas (tabla 1) con el objetivo de prevenir o desinfectar superficies y así erradicar al SARS-CoV-2.

La evidencia sugiere que el SARS-CoV-2 puede permanecer en superficies de contacto, siendo en aerosoles hasta 3 horas, cobre hasta 4 horas, cartón hasta 24 horas, plástico y acero inoxidable hasta 2-3 días ${ }^{(4)}$; basado en estos datos, y pese a la escasa evidencia científica, se realizan múltiples esfuerzos de aplicar sustancias químicas que actúan contra el SARS-CoV-2, sobre toda la superficie del cuerpo de los seres humanos. Esto puede ser perjudicial para la salud de acuerdo a la Agencia de Protección de los Estados Unidos (EPA) ${ }^{(5)}$, ya que estas sustancias solo pueden ser administradas sobre superficies duras y no porosas, concepto que no es aplicable para el ser humano por lo que la exposición a las superficies como las mucosas oral, ocular, dérmica e inhalatoria producen daños a la salud (tabla 2 ).

El concepto de descontaminación por medio de aplicación de sustancias químicas, es un concepto utilizado en la manipulación de agentes biológicos o eventos de exposición de "sustancias químicas peligrosas" HAZMAT (por sus siglas en inglés Hazardous Material), donde el personal debe contar con entrenamiento específico en el manejo de estos escenarios con un equipo de protección personal adecuado, ya que las exposiciones de diferentes sustancias químicas son peligrosas y corren un riesgo de tipo biológico ${ }^{(6)}$.

La mayoría de los dispositivos usados para la aplicación de las sustancias químicas conlleva a valorar varios aspectos: Por ejemplo, las sustancias químicas (elección adecuada, concentración necesaria para la inactivación del SARS-CoV-2); la infraestructura (tamaño estándar, sistema de adecuado almacenamiento y eliminación, sistemas de extracción de aerosoles, tiempo estandarizado de exposición de la sustancia química con la superficie, entre otros) ${ }^{(5)}$.

No se debeaplicarsustancias químicas demanera directa a los seres humanos en el ámbito extrahospitalario ni intrahospitalario, y valorar los dispositivos usados con este propósito, ya que conduce a efectos nocivos a la salud, y crean una falsa sensación de protección en las personas, lo que podría desviar su atención de las medidas básicas que brindan seguridad y eficacia comprobadas como: distanciamiento social, lavado de manos frecuente, uso de mascarillas, y técnica de etiqueta para el estornudo.

Moisés Torres-Maure ${ }^{1,2, a}$, Elvia Ximena Tapia-
Ibáñez $^{2, a}$, Jesús del Carmen Madrigal-Anaya $a^{2, b}$,
Miguel Antonio Canul-Caamal ${ }^{2, b}$.

1. Departamento de Emergencia y Cuidados Críticos, Hospital Cayetano Heredia. Lima, Perú.

2. Centro de Información y Asistencia Toxicológica, Hospital Juárez de México. CDMX, México.

a. Médico Residente de Alta Especialidad en Toxicología Clínica.

b. Médico Toxicólogo Clínico. 
Tabla 1. Modificada de la Lista N: Desinfectantes contra el SARS-CoV-2. United States Environmental Protection Agency (EPA).

\begin{tabular}{|c|c|c|c|c|c|c|}
\hline $\begin{array}{c}\text { Ingrediente } \\
\text { Activo }\end{array}$ & $\begin{array}{c}\text { Nombres de algunos } \\
\text { productos en el } \\
\text { mercado }\end{array}$ & $\begin{array}{l}\text { Producto } \\
\text { útil para que } \\
\text { virus }\end{array}$ & $\begin{array}{l}\text { Tiempo de } \\
\text { contacto } \\
\text { necesario para } \\
\text { desinfección } \\
\text { (minutos) }\end{array}$ & $\begin{array}{c}\text { Tipo de } \\
\text { formulación }\end{array}$ & $\begin{array}{c}\text { Sitio en el } \\
\text { que se debe } \\
\text { utilizar }\end{array}$ & Superficie \\
\hline $\begin{array}{l}\text { Amonio } \\
\text { Cuaternario }\end{array}$ & $\begin{array}{l}\text { Barbicide, maquat } 64 \text {, } \\
\text { lysol, maquat } 128 \mathrm{PD}\end{array}$ & $\begin{array}{l}\text { Coronavirus } \\
\text { humano }\end{array}$ & $\begin{array}{l}10 \text { minutos } \\
\text { (promedio) }\end{array}$ & Diluible & $\begin{array}{l}\text { Nivel } \\
\text { hospitalario, } \\
\text { institucional }\end{array}$ & $\begin{array}{l}\text { Duro no } \\
\text { poroso }\end{array}$ \\
\hline $\begin{array}{l}\text { Peróxido de } \\
\text { hidrógeno }\end{array}$ & Maguard & $\begin{array}{l}\text { Coronavirus } \\
\text { humano }\end{array}$ & $\begin{array}{l}10 \text { minutos } \\
\text { (promedio) }\end{array}$ & Diluible & $\begin{array}{l}\text { Nivel } \\
\text { hospitalario, } \\
\text { institucional }\end{array}$ & $\begin{array}{l}\text { Duro no } \\
\text { poroso }\end{array}$ \\
\hline $\begin{array}{l}\text { Hipoclorito } \\
\text { de sodio }\end{array}$ & $\begin{array}{l}\text { Austin's A-1 Ultra } \\
\text { Disifecting Bleach, } \\
\text { Austin's A-1 } \\
\text { concentrated bleach } \\
8.25 \% \text {, hydris, caltech }\end{array}$ & $\begin{array}{l}\text { Coronavirus } \\
\text { humano }\end{array}$ & 5-10 minutos & Diluible & $\begin{array}{l}\text { Nivel } \\
\text { hospitalario, } \\
\text { institucional }\end{array}$ & $\begin{array}{l}\text { Duro no } \\
\text { poroso }\end{array}$ \\
\hline
\end{tabular}

Tabla 2. Efectos adversos de las sustancias químicas utilizadas. Elaboración propia(7-10).

\begin{tabular}{|c|c|c|c|c|}
\hline Efectos adversos & Ocular & Dérmica & Oral & Inhalatoria \\
\hline $\begin{array}{l}\text { Amonio } \\
\text { cuaternario }\end{array}$ & Conjuntivitis tóxica & $\begin{array}{l}\text { Dermatitis por contacto, } \\
\text { quemaduras químicas } \\
\text { leves-moderadas }\end{array}$ & $\begin{array}{l}\text { Quemadura cáustica, } \\
\text { hipersalivación, emesis, } \\
\text { hematemesis, diarrea. }\end{array}$ & $\begin{array}{l}\text { Broncoconstricción, } \\
\text { edema a nivel alveolar }\end{array}$ \\
\hline $\begin{array}{l}\text { Peróxido de } \\
\text { hidrógeno }\end{array}$ & $\begin{array}{l}\text { Erosión conjuntival, } \\
\text { ulceración, perforación y } \\
\text { laceración, conjuntivitis } \\
\text { química, dolor ocular, }\end{array}$ & $\begin{array}{l}\text { Erosiones dérmicas, } \\
\text { ulceraciones, } \\
\text { vesículas, laceraciones, } \\
\text { eritema, prurito, }\end{array}$ & $\begin{array}{l}\text { Quemaduras del tracto } \\
\text { gastrointestinal, náuseas, } \\
\text { emesis }\end{array}$ & Neumonitis química \\
\hline $\begin{array}{l}\text { Hipoclorito de } \\
\text { sodio }\end{array}$ & $\begin{array}{l}\text { Irritación, epifora, } \\
\text { quemaduras a nivel } \\
\text { corneal, conjuntival, } \\
\text { tejido epiescleral, } \\
\text { fotofobia, ulceración, } \\
\text { opacidades }\end{array}$ & $\begin{array}{l}\text { Quemaduras graves, } \\
\text { dermatitis irritativa, } \\
\text { pérdida temporal del } \\
\text { cabello, úlceras }\end{array}$ & $\begin{array}{l}\text { Emesis, náusea, } \\
\text { hematemesis, quemadura } \\
\text { tracto gastrointestinal }\end{array}$ & $\begin{array}{l}\text { Al contacto se } \\
\text { convierte: ácido } \\
\text { clorhídrico y ácido } \\
\text { hipocloroso, sensación } \\
\text { cuerpo extraño en } \\
\text { garganta, quemadura } \\
\text { de vía aérea, disnea, } \\
\text { tos, neumonitis } \\
\text { química }\end{array}$ \\
\hline
\end{tabular}

\section{Correspondencia:}

\section{Moisés Torres Maure}

Hospital Cayetano Heredia, Departamento de Emergencia y Cuidados Críticos.

Av. Honorio Delgado 262, San Martín de Porres, Lima, Perú

Correo electrónico: moisestorresmaure@gmail.com ; moises.torres.m@upch.pe

\section{REFERENCIAS BIBLIOGRÁFICAS}

1. World Health Organization. Coronavirus Disease (COVID-19) Situation Reports. Geneva: World Health Organization; 2020. (Citado el 1 de octubre de 2020). Disponible en: https://www.who.int/ emergencies/diseases/novel-coronavirus-2019/ situation-reports

2. Infobae. Controversia por el uso de túneles sanitizantes en México por coronavirus: ¿representan un riesgo o 
beneficio? Buenos Aires: Infobae; 2020. (Citado el 8 de octubre de 2020). Disponible en: https://www. infobae.com/america/mexico/2020/04/09/ controversia-por-el-uso-de-tuneles-sanitizantesen-mexico-por-coronavirus-representan-un-riesgo-obeneficio/

3. Diario El Peruano. OPS: Uso de productos químicos en túneles de desinfección es nocivo para las personas. Lima: Diario El Peruano; 29 de abril del 2020. (Citado el 8 de octubre de 2020). Disponible en: https://elperuano.pe/noticia-ops-uso-productosquimicos-tuneles-desinfeccion-es-nocivo-parapersonas-95148.aspx

4. Van Doremalen N, Bushmaker T, Morris DH, et al. Aerosol and Surface Stability of SARS-CoV-2 as Compared with SARS-CoV-1. N Engl J Med. 2020; 382(16):1564-7.

5. United States Environmental Protection Agency. List $\mathrm{N}$ : Disinfectants for Coronavirus (COVID19Washingotn DC: United States Environmental Protection Agency; 2020 (Citado el 1 de octubre de 2020). Disponible en: https://www.epa.gov/pesticideregistration/list-n-disinfectants-coronavirus-covid-19

6. Jaffin R. Hazardous material (HAZMAT) life cycle management: corporate, community and organizational planning and preparedness. Boca Raton, FL: CRC Press; 2013.
7. Hospital Clínico de la Mutual de Seguridad C.Ch.C, Clínica Los Coihues, Hospital San Borja Arriarán, et al. Antisépticos y desinfectantes: apuntando al uso racional. Recomendaciones del Comité Consultivo de InfeccionesAsociadas a laAtención de Salud, Sociedad Chilena de Infectología. Rev chil infectol. 2017; 34(2): 156-174. Doi: 10.4067/S0716-10182017000200010

8. Agency for Toxic Substances and Disease Registry. ToxFAQs $^{\mathrm{TM}}$ - Cloro (Chlorine). Washington DC: Agency for Toxic Substances and Disease Registry; 2019. (Citado el 1 de octubre de 2020). Disponible en: https://www.atsdr.cdc.gov/es/phs/es phs172.html

9. Agency for Toxic Substances and Disease Registry. Peróxido de hidrógeno (Hydrogen Peroxide). Washington DC: Agency for Toxic Substances and Disease Registry; 2019. (Citado el 1 de octubre de 2020). Disponible en: https://www.atsdr.cdc.gov/es/ toxfaqs/es_tfacts $174 . h t m l$

10. New Jersey Department of Health. Hoja Informativa sobre Sustancias Peligrosas. New Jersey: New Jersey Department of Health (Citado el 1 de octubre de 2020). Disponible en: https://nj.gov/health/eoh/ rtkweb/documents/fs/1707sp.pdf?q=1707

Recibido: 30/10/2020 Aceptado: 10/12/2020 